\title{
Co-creating Positive Working Environments: a meta mediation perspective
}

\section{Treasa Kenny}

\begin{abstract}
This article is a practitioner reflection on taking a meta mediation perspective on working with two organizations in co-creating a positive and constructive working environment. This perspective is grounded in the theoretical framework of strategic conflict management systems. The approach taken is to consider a specific process for engaging with organizations by looking at the two case study organizations - one small and growing, the other medium-sized and resource-constrained. The reflection first considers the antecedents for both organizations in engaging in this way. It then sets out the process for whole organization engagement through dialogue. The outcomes for each organization are then shared. The conclusion reached is that both organizations benefited from the engagement in terms of improvements in work environment, working relationships, conflict competence and organizational performance. Some of the ethical considerations for mediators working with organizations in this way are reflected on including neutrality and impartiality, confidentiality and self-determination.
\end{abstract}

\section{Keywords}

Strategic Conflict Management Systems, Meta Mediation, conflict, conflict resolution, organisations, workplace.

\section{Co-creating Positive Working Environments: a meta mediation perspective}

Working environments are places where people spend significant amounts of time. The physical environment ensures the space is conducive to the work to be done. The competence and resources to do the work needed allows people to make their contribution. The working relationships support the delivery of the best work possible - through professional and social interaction. Work environments will always be prone to conflict because of the differences in goals and values that may exist, the different understandings of what needs to be done, how best to do things and the working relationships of those doing the work. Organizations may choose to engage constructively with that reality or to wait for it to manifest more negatively or destructively - and then seek to resolve or manage it. This means that there are many ways in which mediators work with and within organizations. In some instances, we work by 
transaction within the rights and interest-based dimensions of organizations' conflict management systems. This may include collective negotiations, appeals, investigations, mediations, coaching sessions, group facilitations or training courses where the organizations' managers or human resources managers take full responsibility for following up on outcomes. In other instances, we work in potentially more transformative ways that could be considered similar to organizational development.

Working in this more transformational way with organizations requires mediators to recognize that we are working in a larger field of conflict engagement where our conflict competence provides us with the ability to practically interact with organizations in various different roles (Mayer 2004: 13). Mayer (2004) encourages those of us working in the conflict resolution field to live up to our potential for changing the way that conflict is handled in organizations. Meta mediation - a mediation about mediation and other processes of conflict management (Constantino and Sickles Merchant, 1996) - offers an opportunity to realise that potential. It enables the mediator to become more involved in the centre of conflict or decision-making processes so that it becomes less and less the case that people have to be persuaded, cajoled or mandated to use mediation and related services. We can also co-create with organizations a process which focuses on the integrative potential of conflict taking a needs-based approach with an emphasis on communication and particularly dialogue (Mayer, 2004).

Inherent to this approach to working with organizations is a commitment to empowering all participants through taking both a process focus and a system focus (Mayer, 2004: 35). This system focus, where a system is defined as "a bounded transformation process", identifies the conflict management system (CMS) within organizations as transforming conflict into cooperation and disputes into settlements within the boundaries of the organization (Lipsky \& Avgar, 2008:150). This is very much based on the concept of shared management and prevention of destructive conflict across the organization rather than simply the resolution of disputes through written complaints, grievances, or lawsuits (Avgar, 2010; Roche and Teague, 2011; Doherty and Teague, 2013; Roche et al., 2014).

The next section of this article looks more closely at two case studies of organizations in Ireland who engaged with this mediator in co-creating a positive working environment. This is done with the focus of the practitioner being intentional in the work undertaken, to reflect in action, to learn continually from experience and to develop my own habits and disciplines of reflective practice (Lang \& Taylor, 2000: 235).

\section{Antecedents: What led these two organizations to engage in this way?}

The first organization $(\mathrm{S} \& \mathrm{G})$ is a small company which wanted to survive and grow through the economic challenges in Ireland at the point of engagement in July 2010. The two owner-managers had a four-person operational management team, and forty articulate staff as well as a predominantly young, culturally diverse population of clients. The organization had faced some difficult decisions in 2009 which had resulted in reductions in salary for all managers and staff to ensure the business would survive in the short term. There is no trade union presence in the organization. By 2010, the business was beginning to grow again, despite the continuing recession, due to a good deal of effort and hard work by all, and the 
increasing demands were leading to tensions.

The second organization (Msac) is medium-sized, diverse in its mix of 40 managers and $400+$ staff who need to support each other in delivering an important service. The organization recognizes a number of trade unions for negotiation and representation. The organization has been continuing on a journey of change in recent years while facing increasing demand for the service and limited resources. This had led to an increasing pattern of tension across working relationships and the Occupational Health and HR managers had commissioned an evaluation of the organizational climate through an external research group. The point of engagement with the mediator was April 2012 when the results of that survey had been received and considered by the senior management team.

For both organizations, they were experiencing tensions in working relationships and their goals were similar in that they each wanted a constructive and successful working environment, based on cooperative and collaborative working relationships. Both these organizations, like others, 'focussed on generating commitment, and high performance may seek to develop processes for solving workplace problems expeditiously and fairly to avoid problems escalating or relations becoming embittered' (Colvin, 2004 cited in Roche and Teague, 2011: 440). Informal methods of resolving conflict that improve 'communication, information sharing and exchange of ideas' have been identified as being of particular significance (Avgar, 2010: 253) with an emphasis on a strategic or transformational rather than a transactional approach to conflict engagement (Saundry and Wibberley, 2014: 3). The process is set out in the next section.

\section{Process}

Co-creating positive working environments requires engagement and conversation. Some of that engagement and conversation is uncomfortable for people to consider - and uncomfortable for them to enter directly into. Co-creating the map of the current territory of the working environment, visioning the working environment that will be most positive to the different needs that will exist, planning for what will have to be done as well as agreeing the stopping points along the way to check in on progress are important elements to be mediated.

There is no "one size fits all", and as with the overall framework of strategic conflict management systems, effective meta mediation requires the mediator to adopt a configurational framework for conflict management rather than taking a universalistic or "best practice" perspective (Lipsky \& Avgar, 2008: 171). That means that co-creating positive working environments requires creativity in supporting the organization and the people within it to create their present and future. Engaging all in telling their story, building the shared working agenda with a future focus, exploring options, reality testing, reaching an agreed plan, reviewing progress and continuing forward are all familiar and yet different. The model developed to illustrate this process is set out in Figure1. 


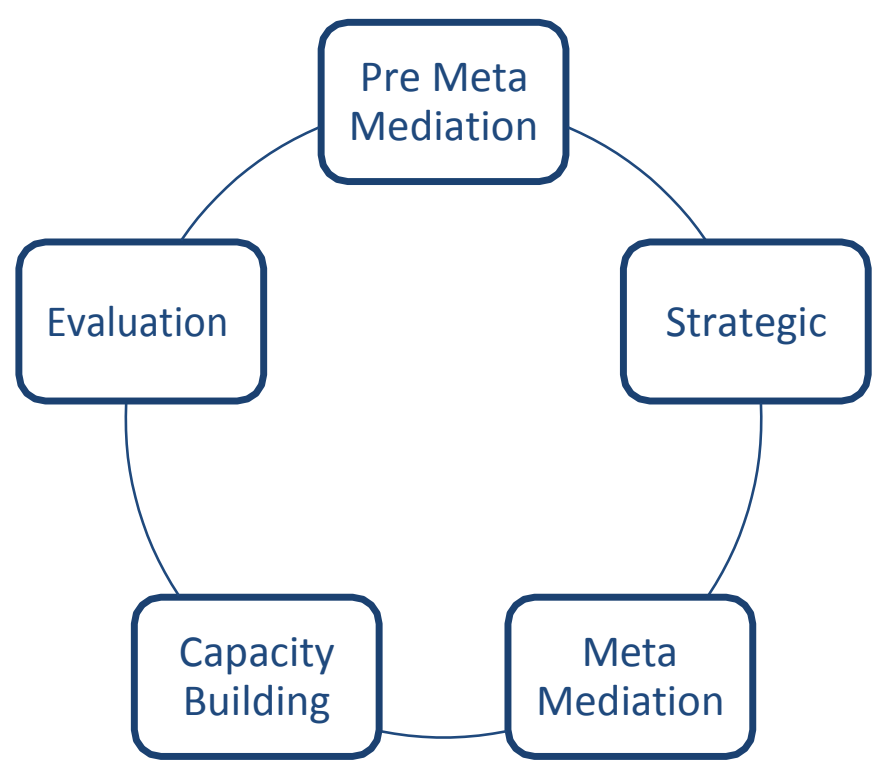

Figure 1: Five Phase Process for Co-creating Positive Working Environments

\section{Phase 1: Pre Meta Mediation}

Pre mediation meetings in the individual process of mediation allow the mediator to understand the individual's issues and needs, and explain the process. Pre meta mediation seeks to understand the issues by hearing the voices of those involved relate their perspective on the issues, be heard in relation to their needs for the work environment and inform the process that they will be engaged in. There is clarity that what is said is not attributed to any individual but becomes a part of the shared agenda.

The first organization, S\&G, engaged with the mediator in pre meta mediation in August 2010. There were individual meetings with the two owner/managers and four operational managers. At that point that was the extent of the initial discussions.

The second organization, Msac, entered into the pre meta mediation phase in November 2012. This involved focus groups and interviews with managers and staff from across the organization, who wished to participate at that point, in identifying what support and engagement could best help them create a more positive working environment than the one identified through the first survey findings which had been communicated to all those working in theorganization.

\section{Phase 2: Strategic}

The strategic phase (based on the strategic style of mediation identified by Kressel, 2007) is where the mediator, having heard from all those involved, prepares a shared agenda and identifies the range of options available to the organization. The co-creation of the process requires that a number of options are discussed and the 'best fit' configuration agreed on. It also requires that agreements are reached in relation to communication and feedback, resources, process timeframe and evaluation. 
The first organization, S\&G, entered the strategic phase in September 2010 with feedback from the mediator to the whole management team on the shared agenda generated from those individual meetings. The dialogue with that team over the course of a half day led to their exploring and reaching agreement on some issues and agreeing that all those working in the organization needed to be involved in a conversation about a number of other issues. The options for engaging everyone in co-creating a positive working environment were explored at a further meeting. All those working in the organization were given an opportunity to inform the agenda through their own team structure or by making individual telephone contact with the mediator.

The second organization, Msac, entered the strategic phase in December 2012 with feedback from the mediator to the senior management team on the shared agenda generated from those individual meetings and focus groups. The dialogue with that team took place on a number of occasions through to end January 2013. During those various meetings a plan was developed in relation to co-creating a positive working environment which would be supported and resourced by the senior management team. It was also agreed that a positive working environment group would be set up to plan, do and review the process set out in theplan.

\section{Phase 3: Meta Mediation}

Meta mediation is the bringing together of people from across the organization for dialogue to take place. The process for any dialogue is clearly explained in advance and at the beginning of the session itself. What will happen next with any agreed actions is also discussed at the beginning and end of the session.

The first organization, S\&G, came together in January 2011 for a whole organization conversation where they addressed the shared agenda through dialogue. To ensure everyone had a chance to have their voice heard, the issues were initially discussed in small groups and then explored further in the larger group. There was robust conversation and the session culminated with clear understandings and agreements about the best way of working together, of sustaining the conversation together and of addressing conflict constructively. The group also discussed how they would monitor and evaluate progress.

The second organization, Msac, came together in mixed groups - staff from across the organization and managers - from April 2013. The positive working environment group met quarterly and reported to the Senior Management Team on progress on that same basis. All staff and managers participated in dialogue groups to talk with one another about their work environment and needs from each other. Various initiatives were identified as well as co-creating with people in the organization their own agreed behaviours and communication for cooperation and collaboration. It was agreed by all that this would back-up the organization's Dignity at Work Policy with an informed understanding of what was important about informal resolution of conflict as a first step. It was also identified that colleagues and managers needed to "notice" conflict in its early stages and seek support to resolve it. 


\section{Phase 4: Capacity Building}

Conflict competence is not necessarily something which managers or staff within organizations have developed. Co-creating structures and processes to build internal capacity is essential.

The first organization, $S \& G$, put in place conflict coaching for the two owners/managers and four managers in 2011. The organization committed to providing this support to all new managers whether promoted internally or recruited externally. The agreement reached at the Meta Mediation session was that managers would build their capacity to address conflict constructively through dialogue with the staff concerned. If the issues could not be resolved in this way, then a mediator would be asked to support people in finding a workable solution if possible.

The second organization, Msac, put in place a comprehensive capacity building programme. Conflict resolution skills and conflict coaching training was provided to all senior managers, and then all managers during 2014. Conflict resolution skills training is on the 2015 calendar for staff. Diversity workshops and resilience workshops, which had been identified as important through the process, were put in place.

\section{Phase 5: Evaluation}

The sustainability of co-creating positive working environments requires that organizations are willing to review and evaluate progress. The engagement with both organizations developed through dialogue - which included review and learning - which then strengthened the next phase.

The first organization, $S \& G$, have held a review session for the whole organization each year from 2012 onwards. Where conflicts have arisen, early dialogue between people has been facilitated by the organization. One important outcome is that the work environment is confirmed by all as continuing to be positive at those annual reviews - the reality has included conflict and its early resolution. A second important outcome is that the business has achieved high performance and continued success, including external industry awards.

The second organization, Msac, repeated the work environment survey in 2013 and 2014 continuing to use an organization separate to the mediator. The results of the survey have been extremely positive with a marked improvement in the perception of management support and communication. The organization's change programme is continuing apace and an international standards audit was impressed by the investment in the working environment and working relationships and the return through productivity and performance. This organization has also been a finalist for an award.

Both organizations have demonstrated a continuing commitment to sustaining a positive working environment. The first organization, $S \& G$, continues to support coaching for all new managers and ongoing annual dialogue with the whole organization. Where conflict has arisen, individuals have been supported through conflict coaching sessions with no need, to date, for any further engagement as individuals addressed the issue directly and a workable solution was found. The second organization, Msac, has refreshed membership of its positive working environment group and continues to work with 
an annual plan. The organization continues to invest in that group being chaired by the mediator and this role is reviewed annually with the group. The organization has also identified and sought mediation support to engage with individual and team conflicts.

In considering the practice and the theory, both these organizations demonstrate that they are engaged organizations with 'strong authentic values, with clear evidence of trust and fairness based on mutual respect and reciprocal commitments between employers and employees' which develops the social capital generated by interactions between people in organizations (Avgar, 2010: 237). In both organizations, there obviously continue to be conflicts because that is a reality in the work environment. However, considering the measures of an effective conflict management system, it is evident that people are managing their conflicts constructively now; there is evidence of increased staff satisfaction; there are decreased costs as neither organization has had recourse to formal procedures during the timeframe of the meta mediation; there is evidence (profit, survey and international standards audit) of increased productivity and improved relationships generally within the organizations (Constantino and Sickles Merchant, 1996; Lipsky, Seeber and Fincher, 2003).

\section{Taking a critical perspective}

Both organizations invested people, time and money in co-creating positive working environments. They also persevered in changing habits and patterns of behaviour as well as in building conflict competence. Even in such conducive circumstances there are some ethical dilemmas that present for the mediator around neutrality and impartiality, confidentiality and self-determination in meta mediation as they do in mediation itself - with the ensuing potential for a mismatch between ethics and practice (Van Gramberg, 2006).

As mediators, we need to appreciate that power relations are underpinned by the organizational context within which mediation takes place and are also reflected in the way in which managers interact with the mediation process. Meta mediation raises the neutrality and impartiality dilemma because the mediator is paid by the organization and due care and consideration needs to be given to the need to balance power and opportunities for engagement between all those engaged in meta mediation. In his study of management consultants, Williams (2001: 519 in Van Gramberg, 2006) noted that 'consultants are not objective, they look to please clients, attempting to secure the next piece of work'. The nature of this relationship then may "reinstall" power dynamics by the mediator being pressured by the "more powerful party to speed up the process [rather] than [attending] to the need of the less powerful party to vent opinions and emotions." (Bollen et al. 2010: 632). This balancing of power can be seriously tested particularly where senior managers own emotional responses to conflict lead to them wanting to move quickly through some steps in the process or, indeed, avoid some steps.

Confidentiality may be difficult to maintain within a working environment and may restrict the extent to which organizations can learn from mediation processes to review and improve workplace practice. Informal discussions by mediators with the organization are also identified in the literature as a 
challenge to neutrality and confidentiality of the mediation process (Mayer, 2004). This needs very real consideration in relation to meta mediation. Dialogue and agreements around what will be shared, with whom, and how it will be shared need to clear and agreed with all those participating. This was particularly relevant in the above case studies at the pre mediation stages and evaluation stages.

Meta mediation requires the mediator to ensure that managers, staff and trades unions - where they are in place - share responsibility for co-creating the positive working environment and do not attempt to abrogate their responsibility to the mediator (Van Gramberg, 2006). Co-creating the process with all those working in the organization is essential so that people engage on the basis of making informed decisions at each phase so that self-determination through dialogue exists. In meta mediation, as in mediation more generally, mediators need to recognise the fundamental power relationships that exist in the organization (Banks and Saundry, 2010: 16) and only continue their engagement where all those involved demonstrate continued commitment and consistent behaviour.

In summary, cohesion and commitment are identified as essential aspects of a high-performing workforce (Lipsky et al., 2003; Avgar, 2010; Roche and Teague, 2011; Roche et al., 2014) which is fundamentally about the social contract (Lipsky et al., 2003: 32) and working relationships between employees and between employees and the employer. Meta mediation, as a process, needs to engage the organization in dialogue on the work environment and the design of conflict engagement processes to increase the likelihood that resulting processes could be used. Fostering the motivation, skills and resources necessary to support the effective use of the procedures and processes, confidence on the part of the people that they will not suffer retaliation for raising issues, as well as the delegated authority to managers to resolve conflict, and the provision for informal as well as formal contacts between people are all key. 


\section{References}

Avgar, A. C. (2010) "Negotiated Capital: conflict, its resolution, and workplace social capital". International Journal of Conflict Management, 21(3): 236-259.

Banks, L. \& R. Saundry, (2010) "Mediation: a panacea for the ills of workplace dispute resolution? A Comprehensive Review of the Literature examining Workplace Mediation. iRowe Research Paper No.1. University of Lancashire, England.

Bollen, K., M. Euwena, \& P. Muller, (2010) "Why are Subordinates Less Satisfied with Mediation? The Role of Uncertainty. Negotiation Journal, 26(4): 417-433.

Constantino, C.A. and C. Sickles Merchant, (1996) Designing Conflict Management Systems: A Guide to Creating Productive and Healtby Organisations. USA:Jossey-Bass.

Kressel, K. (2007) “The Strategic Style in Mediation”. Conflict Resolution Quarterly, 24(3): 251-283.

Doherty, L. \& P. Teague, (2011) "Conflict Management Systems in Subsidiaries of Non Union Multinational Organisations located in the Republic of Ireland". The International Journal of Human Resource Management, 21(1): 57-71.

Lang, M. D. and A. Taylor, (2000) The Making of a Mediator: Developing Artistry in Practice, San Francisco: Jossey-Bass.

Lipsky, D.B., R. L. Seeber, \& R.D. Fincher, (2003) Emerging Systems for Managing Workplace Conflict. USA: Jossey-Bass.

Lipsky, D. B., \& A. C. Avgar, (2008) “Toward a Strategic Theory of Workplace Conflict Management”, Journal of Dispute Resolution, Heinonline.

Mayer, B. (2004) Beyond Neutrality: Confronting the Crisis in Conflict Resolution. San Francisco: Jossey-Bass.

Roche, W.K. \& P. Teague, (2011) “The Growing Importance of Workplace ADR”, International Journal of Human Resource Management, 23(3): 447-458.

Roche, W.K., P. Teague, \& A. Colvin, A. Eds (2014) The Oxford Handbook of Conflict Management in Organizations. UK: Oxford University Press.

Saundry, R. \& G. Wibberley, (2014) "Workplace Dispute Resolution and the Management of Industrial Conflict. A Thematic Analysis of five Case Studies. ACAS Research Paper 06/14. UK.

Van Gramberg, B. (2006) Managing Workplace Conflict: Alternative Dispute Resolution in Australia. Sydney: The Federation Press 
Treasa Kenny, FCIPD, M.MII has worked within and with organizations for 30 years. Over the past decade, she has been engaging with organizations across the whole continuum of the conflict management system. This portfolio includes co-creating positive working environments, developing conflict competence, coaching in constructive communication, facilitating conversations, mediation, investigation, appeals and external adjudication processes. Treasa's work with organizations involves her with front line staff, operational managers, trade union representatives and strategic managers as well as Boards.

Treasa is a Partner in Burtenshaw Kenny Associates. She is a Practitioner member of the Mediators' Institute of Ireland and served on Council for seven years. Her background is in human resource management and she is a Fellow of the Chartered Institute of Personnel Management.

Treasa has chosen the path of "pracademic" (Susskind, 2013) through supporting her professional practice with ongoing education of herself and supporting others in their continued development. In addition to her professional qualifications, she has a Master's in Education, Training and Development and a Masters in Conflict Intervention and Mediation. She is currently undertaking a $\mathrm{PhD}$ (part-time) through University College Dublin and her research interest is workplace mediation and conflict management systems. She is a Module Coordinator for the Maynooth University Postgraduate Certificate for Organisation and Workplace (Masters in Mediation and Conflict Intervention), and works as an occasional lecturer on programmes in Maynooth University and University College Dublin. 